\title{
Practice Research on Strengthening Humanistic Quality Education of Nursing Students in "Six Hearts" Nursing Service
}

\author{
Xiaofeng Li ${ }^{1}$, Lanian Chen ${ }^{1,}$, Xiaojuan Chen ${ }^{1}$, Huiqin $\mathrm{Li}^{2}$, Xiangjing $\mathrm{Xu}^{3}$, Li Zhu ${ }^{4}$, Aiping Yu ${ }^{5}$, \\ Lu $\operatorname{Tan}^{1}$ \\ ${ }^{1}$ The Department of Nursing, Second People's Hospital of Three Gorges University, Yichang Second People's Hospital, Yichang, China \\ ${ }^{2}$ The Department of Five Officials, Second People's Hospital of Three Gorges University, Yichang Second People's Hospital, Yichang, China \\ ${ }^{3}$ The Department of Cardiology, Second People's Hospital of Three Gorges University, Yichang Second People's Hospital, Yichang, China \\ ${ }^{4}$ The Yichang Second People's Hospital Operating Room of the Second People's Hospital of Three Gorges University, Yichang, China \\ ${ }^{5}$ The Department of Oncology, Second People's Hospital of Three Gorges University, Yichang Second People's Hospital, Yichang, China
}

Email address:

498502904@qq.com (Lanian Chen)

${ }^{*}$ Corresponding author

\section{To cite this article:}

Xiaofeng Li, Lanian Chen, Xiaojuan Chen, Huiqin Li, Xiangjing Xu, Li Zhu, Aiping Yu, Lu Tan. Practice Research on Strengthening Humanistic Quality Education of Nursing Students in "Six Hearts" Nursing Service. American Journal of Nursing Science.

Vol. 8, No. 2, 2019, pp. 43-47. doi: 10.11648/j.ajns.20190802.12

Received: January 5, 2019; Accepted: February 13, 2019; Published: March 1, 2019

\begin{abstract}
The discussion is based on "enthusiastic reception, patient speaking, careful observation, sincere help, warm heart, loving visit" (hereinafter referred to as "six hearts") Objective: To explore the practical effect of "six hearts" nursing service process on improving nursing students' humanistic quality. Methods: Taking nursing undergraduates from a medical college in 2016 and 2017 as the research object, 82 nursing undergraduates in 2016 were set as the control group, clinical nursing teaching was carried out by traditional teaching methods, and 84 nursing undergraduates in 2017 were set as the observation group. The "six - heart" nursing service process education was added to the traditional teaching methods, and the humanistic quality scores of the two groups of nursing students were compared. Results: the scores of humanistic accomplishment in the observation group were significantly higher than those in the control group (all p \& lt; 0.01). Conclusion: The "six hearts" nursing service flow runs through clinical nursing students' teaching, which is conducive to improving nursing students' clinical communication ability and humanistic quality, laying a good foundation for reserving excellent nursing professionals and ensuring nursing quality while improving the teaching level of nurses.
\end{abstract}

Keywords: "Six Hearts" Nursing Service Process, Nursing Students, Communication Skills, Humanistic Quality, Education

\section{Introduction}

At present, the tension between nurses and patients and the increase in medical disputes are related to the communication ability of nursing staff, mostly caused by factors such as medical seeking private benefits, i.e. medical humanistic defects [1]. With the improvement of people's living conditions, the requirements for the humanistic quality of medical staff are also increasing day by day. Watson [2] believes that the ability of nursing humanistic care is the ability of nurses to externalize their inherent humanistic quality into serving the patient's behavior. However, most of the students who go to clinical practice in major nursing colleges and universities receive professional theoretical education in school, but their humanistic care ability is generally insufficient when nursing patients, and they lack good communication and humanistic care ability [3] How to improve the humanistic quality and caring ability of nursing students is a big issue facing major teaching hospitals. Caring for patients is the basic quality and ability of nurses, including mental and social care for patients and professional and technical care [4]. Teaching hospital is an important place for 
training nurses' clinical experience, and it is an important task and duty for all nurses' teachers to carry out humanistic quality education for nursing students. At present, clinical teaching pays more attention to the training of specialized theory and operation. The whole teaching activity always implements the educational concept of " training higher nursing talents with equal emphasis on professional skills and comprehensive humanistic quality" [5]. This article will report and summarize the achievements of the "six - heart" nursing service process of "enthusiastic reception, patient speaking, careful observation, sincere help, warm heart delivery and loving visit" in the humanistic quality teaching of nursing students in clinical practice for 8 months as follows.

\section{Data and Methods}

\subsection{General Information}

A total of 166 nursing undergraduates of 2016 - 2017, 128 women and 38 men, aged $19-21$, were selected as the research objects. In 2016, 82 interns were set as control group, using traditional teaching methods. In 2017, 84 people were set up as study group and taught with the "six hearts" nursing service model. There was no significant difference between the two groups in terms of basic education, age and school learning $(\mathrm{P}>0.05)$, which was comparable.

\subsection{Teaching Methods}

\subsubsection{The Control Group}

The control group was taught with conventional clinical teaching methods, and the nursing students were instructed by the teachers to carry out various basic nursing techniques and observe their illness. According to the traditional teaching method, theoretical operation assessment and satisfaction rate survey are conducted every month.

\subsubsection{The Observation Group}

The observation group added "six hearts" nursing service flow education to the traditional teaching to carry out clinical teaching. According to the characteristics of the disease, each specialty formulates the standard of "six hearts" nursing service in the department, formulates the training plan for interns, provides theoretical training to teachers on the content and standard of "six hearts" nursing service in this specialty, and runs the "six hearts" nursing service process through nursing teaching rounds and nursing humanistic care case discussions. Clinical teaching teachers should strengthen communication with nursing students before teaching, fully understand the psychological quality, communication ability, specialty theory and humanistic care ability of nursing students, and design teaching programs accordingly. The head nurse of each department takes part in the shift in the morning and evening, takes questions at any time, conducts theoretical examination once a week, and ensures that all the students pass the examination. Due to the lack of understanding of the "six - heart" nursing service process for nursing students who have just arrived at the hospital for practice, all teachers are required to give a trial talk in person before the nursing students communicate with patients, so as to help nursing students master relevant nursing skills and nurse-patient communication skills. The following introduces the teaching method of "six hearts" nursing service flow by taking Chinese medicine as an example. Each year, the departments collectively discuss and revise the "six - heart" nursing service contents and assessment standards, formulate training plans, and strengthen the assessment by the department quality control team to ensure that everyone can master them. All students in the internship program are taught by teachers, earnestly study the requirements of nursing measures related to "six hearts" in the department, explain the relevant contents in detail, and take the entrance exam.

I. Implement enthusiasm

Under the guidance of teachers, nursing students receive patients from the time they are admitted to hospital, introduce ward environment, rules and regulations, daily living and food precautions of patients according to the department's "six heart" nursing service process, shorten the distance with patients, and solve patients' bad mood.

II. Implement patience

Under the guidance of teachers, nursing students explain the contents of medication, diet, rehabilitation exercise care and so on according to the "six - heart" nursing service flow, giving patients health care knowledge related to their illness free of charge, and improving the awareness rate of patients' relevant knowledge.

III. Implement a careful view

Under the guidance of teachers, nursing students strengthen the observation methods of patients' condition, daily life, diet, sleep, emotion and other aspects according to the "six - heart" nursing service process, and analyze the problems existing in the observation of nursing students such as language, etiquette and other humanistic qualities as well as the lack of specialized theories, with particular attention to the cultivation of communication points in the observation of nursing students' diseases, matters needing attention in patient interaction and privacy protection. Timely guide nursing students to observe and use patient's emotion and patient's feedback of compliance in the "six - heart" nursing service process, strengthen communication in a timely manner in various ways, and gain the trust of patients.

IV. Implement sincere help

Under the guidance of teachers, nursing students regularly inspect wards in accordance with the "six - heart" nursing service process, strengthen early evening care at meals, implement various special nursing measures, and provide free love medicine bags (to promote sleep) and so on.

\section{Implement Wenxin}

Nursing students guide patients' discharge guidance on medication, daily life and rehabilitation matters according to the "six hearts" nursing service process under the guidance of teachers.

VI. Implement love visit

Under the guidance of teachers, nursing students accompany the teachers to the patient's home for home visits 
and other home-based services. Focus on the living habits, medication, disease prevention, rehabilitation training of traditional Chinese medicine and other contents existing during the hospitalization of patients. To enable patients to have an in-depth understanding of the relevant knowledge of disease prevention that should be paid special attention to, to feel the care of medical staff, to eliminate their anxiety caused by the disease and to improve their awareness of disease prevention.

VII. Strengthen supervision and inspection

The head nurse of the department should strengthen the examination of questions during the morning meeting and shift change, and put forward improvement measures in time when problems are found. It also requires teachers to collect students' problems at any time during the teaching process, hold case analysis meetings every week, and require all students to attend the meetings. Teachers mainly listen to students' analysis and summary, and finally answer the collected questions one by one in the form of a unified reply.

\section{Evaluation Method}

At the end of each specialty internship, the teachers in charge of teaching in the department evaluated the scores of humanistic quality of the two groups of nursing students. The humanistic quality evaluation questionnaire was designed by themselves according to relevant domestic and foreign documents. It was divided into five dimensions, namely moral quality, psychological quality, aesthetic quality, scientific quality and interpersonal quality. Each dimension included three items of consciousness, knowledge and behavior, with a total of 15 items. The full score for each dimension is 100 points. For example, the dimension of moral accomplishment includes three items of moral consciousness, moral knowledge and moral behavior, which are 40 points, 30 points and 30 points in turn. The internal consistency Cronbach'sa coefficient of the questionnaire measured in this study is 0.854 .

\section{Statistical Processing}

Using SPSS 19.0 statistical software for data entry and statistical analysis, the measurement data are expressed in $\mathrm{s}$ and $\mathrm{t}$ test, with $\mathrm{p}<0.05$ as the difference being statistically significant.

\section{Results}

The scores of students' humanistic quality after the implementation of the "six - heart" high-quality nursing service process teaching are shown in table 1 .

Table 1. Comparison of humanistic quality scores between two groups of nursing students (Score, $\bar{x} \pm s$ ).

\begin{tabular}{llllll}
\hline Group & The number of & $\begin{array}{l}\text { Moral } \\
\text { accomplishment }\end{array}$ & $\begin{array}{l}\text { Psychological } \\
\text { accomplishment }\end{array}$ & $\begin{array}{l}\text { Aesthetic } \\
\text { accomplishment }\end{array}$ & $\begin{array}{l}\text { Scientific literacy } \\
\text { accomplishment }\end{array}$ \\
\hline Observation group & 84 & $2.29 \pm 0.69$ & $2.16 \pm 0.74$ & $2.18 \pm 0.78$ & $2.16 \pm 0.81$ \\
Control group & 82 & $1.57 \pm 0.63$ & $1.52 \pm 0.59$ & $1.68 \pm 0.63$ & $1.59 \pm 0.58$ \\
T value & & 5.199 & 4.216 & 3.708 & $2.17 \pm 0.67$ \\
P & & $<0.01$ & $<0.01$ & $<0.01$ & 3.293 \\
\hline
\end{tabular}

\section{Discussion}

Nursing students are in a highly plastic stage, which is a critical period to form humanistic quality. How to cultivate high-quality nursing students is currently the key research task of nursing education. Only by starting from the humanistic quality of nursing students, continuously improving their humanistic care ability, and then through the edification of hospital humanistic environment and professional situation, comprehensively improving the humanistic quality of nursing students, can we continuously promote the smooth development of high-quality nursing in hospitals at all levels [6] This requires us to cultivate a high-quality nurse with good professional skills and humanistic qualities. It is also necessary to cultivate the caring spirit of nursing students, whose caring consciousness and humanistic quality will directly affect the quality of nursing [7]. Some studies show that the overall caring ability of our undergraduate students is relatively insufficient, which is lower than the international nursing care ability scoring standard [8]. Nursing education shoulders the important task of training qualified nursing personnel for medical and health care [9]. We should guide nursing students to be patient-centered and understand more about observing the psychological, physiological, social, spiritual and cultural levels of patients. However, nursing humanistic cultivation covers etiquette, aesthetics, communication, ethics and other modules [10]. This puts forward higher requirements for clinical teachers' teaching level, professional quality and communication ability. In our hospital, the "six - heart" nursing service process teaching method was integrated into clinical teaching, and the pertinence of nursing students' communication and operation was enhanced.

\subsection{Impact on Nursing Communication Skills}

Under the guidance of teachers, nursing students warmly received patients according to the requirements of the "six heart" nursing process, explained the relevant requirements of admission notice, introduced the condition of illness, promptly solved the relevant problems encountered by patients when they were admitted to hospital, and quickly shortened the distance with patients, so that nursing students could have a pleasant communication with patients in a short period of time, and the patients' medical experience would be very warm. 
After entering the department, the nursing students in the observation group practiced on the basis of systematic "six hearts" of high-quality nursing-related content training, To ensure that students have a clear and specific reception method and content, and provide a reliable theoretical basis. Can quickly grasp the contents of nursing and communication in various specialties, quickly grasp the humanistic qualities that should be paid attention to when communicating with patients under the guidance of department nurses, and serve patients more confidently in clinical work. It can be seen from Table 1 that students' Humanities accomplishment have been greatly improved. The control group of nursing students had mastered some health education and communication skills under the guidance of teachers, but the learning effect was obviously lagging behind the observation group due to the relative lack of corresponding training and influence.

\subsection{Influence on the Attention of Nursing Students and Humanities}

This study aims to improve the humanistic quality of clinical nursing students from the perspectives of moral quality, psychological quality, aesthetic quality, scientific quality and interpersonal quality [11]. The application of the "six - heart" nursing service concept in clinical teaching requires patient introduction of all kinds of knowledge according to the characteristics of the disease. With the increase of contact time with patients, patients will have more opportunities to ask questions, which virtually puts forward higher requirements for students and improves the interest of nursing students in learning humanistic quality. Because of the need to constantly communicate with patients and integrate professional education with humanistic education when explaining related knowledge, nursing students should receive humanistic quality training from the first day of entering the department, and take teachers to make "six - heart" nursing service content into slides to explain it and give real-time guidance in actual operation, so as to really protect students' clear need for health education and related communication methods and pay attention to etiquette and so on, thus improving the learning ability of nursing students. In the process of nursing, due to mastering the relevant knowledge skillfully, it will be recognized in different environments, further enhancing the enthusiasm of nursing students in learning.

\subsection{Impact on the Interpersonal Skills of Nursing Students}

Nursing students will feel the needs of patients when they communicate with patients in clinical nursing. Nursing students will be internalized into their own humanistic quality through spiritual perception and emotional shock, and their comprehensive ability will be improved rapidly. When the concept of "six - heart" nursing service is not used in teaching, it is a long and arduous process for nursing students to master various health education skills and form humanistic quality. The education of the "six - heart" nursing service concept has played a positive role in helping nursing students to establish correct professional cognition, improve professional identity and strengthen the belief of medical profession by continuously stimulating the deeper motivation of nursing students [12]. Under the guidance of teachers, nursing students patiently explained disease-related knowledge, examination results, hospitalization matters before and after examination, medication knowledge, diet guidance and rehabilitation training in accordance with the requirements of "six-heart" nursing patience. This requires nursing students to strengthen their professional knowledge accumulation and constantly interact with patients, care for patients and improve their communication ability.

\subsection{Impact on the Overall Quality of Nursing Students}

Humanistic care is the core of nursing, an important indicator of high-quality nursing, and a basic duty that nurses must perform [12-13]. Due to the influence of the traditional biomedical model, nursing education in our country has been pursuing the training goal of " professionals" for a long time, ignoring the training of nurses' humanistic quality [14] When the "six - heart" nursing service process was applied to clinical teaching in a tertiary hospital in Yichang city, Hubei province, it played an imperceptible role in promoting the improvement of nursing students' humanistic quality through professional training, case analysis, nurses' words and deeds, and the good humanistic care atmosphere formed by the departments. Teachers bring up common nursing problems and organize nursing experts with teaching experience and patients willing to cooperate together for case analysis and discussion. Nursing students can find deficiencies in the discussion, improve their humanistic care ability in their work, gain general praise from patients in different occasions, and significantly increase patient satisfaction.

\subsection{Impact on the Emergency Response Capacity of Nursing Students}

Under the guidance of the teacher, nursing students learn to use their specialized knowledge while completing treatment care and life care according to the requirements of "six hearts" nursing care and sincere help, strengthen observation of patients' vital signs and collection of patients' general conditions, and learn to interact with patients while improving their observation ability, feel various needs of patients, and learn to think differently. As the number of patients in close contact with teachers increased, some help was given to elderly patients and patients with reduced self-care ability in a timely manner to cooperate with teachers to actively deal with various emergencies and effectively improve students' coping ability.

\subsection{Impact on the Ability of Nursing Students to Collaborate}

Studies have shown that in order to improve students' caring ability, they should first be placed in a caring environment ${ }^{[15]}$. Under the guidance of the teacher, nursing students, according to the requirements of "six - heart" nursing process love visit, use rest time to accompany the teacher to visit the home of 
patients in need, understand the basic situation of patients' physical condition, diet and medication and disease recovery after discharge, learn to use their specialized knowledge to help patients, and students should help each other to complete the visit. Teachers will express trust, concern and appreciation to nursing students in a timely manner, increase interaction, make the relationship between teachers and students harmonious, and improve team spirit, which is of great significance to improve students' interpersonal communication and humanistic quality.

\section{Conclusion}

The "six - heart" nursing service process is used to strengthen nursing students' humanistic care consciousness and cultivate nursing students' caring ability, laying a solid foundation for clinical training of high-quality nursing talents with a combination of professional quality and humanistic quality, and providing guarantee for meeting the health service needs of the people.

\section{Project}

This project is the Yichang science and technology bureau soft science project A17-30311 in 2017.

\section{References}

[1] Peng Sun, Jun guo Chen. Research on the Construction of Humanistic Quality Education System for Nursing Students [D] Third Military Medical University, 2012.11.

[2] Watson J. The Philosophy and science of nursing [M]. Colorado: colorado Associated University Press, 1985:23.

[3] Shuang qin Chen, si jian Li, zhixia Zhang. correlation analysis of school caring environment, caring among nursing students and caring ability of nursing students [J]. journal of nursing, 2009, 16 (11b): 1-3.

[4] Jian er Chen Nursing Humanities [M]. Hangzhou: Zhejiang University Press, 2008.

[5] Shen Xiaoping, Ye Meng. Brand Building and Characteristic Development of Private Higher Vocational Nursing Colleges [J]. China Nursing Education, 2017, 14 (5): 325-329.

[6] Shao Hongying, Zhang Naizheng, Wen Qianyu. Rethinking of Humanistic Nursing Education in Vocational Colleges under the Background of " Demonstration Project of High Quality Nursing Service" [J]. Chinese Medical Ethics, 2015, 28 (6): 1002-1004.

[7] Tian Li. Exploration on the reform of nursing humanities curriculum system [J]. China Nursing Education, 2014, 11 (1): $42-44$.

[8] Zhang Jinhua, Gao Min, Li Wei, et al. Investigation on Current Situation of Humanistic Care Ability of Undergraduate
Nursing Students [J]. China Nursing Education, 2012, 9 (7): 328-330.

[9] Xia Hesheng, Huang Mei, Lu Jianghui, et al. Approaches and Reflections on Humanistic Curriculum Reform of Nursing Major in Medical Higher Vocational Colleges [J]. Chinese Journal of Practical Nursing, 2014, 30 (34): 30-32.

[10] Jiang Yanhong. Talking about the cultivation of humanistic quality in secondary vocational nursing education $[\mathrm{J}]$. Times Education, 2016 (18): 116.

[11] Yang Liang, Zhou Wenjun. Research on the Importance and Countermeasures of Improving Medical Students' Humanistic Quality [J]. Teaching and Educating People. 2015, 12 (18): 35-37.

[12] Liu Yilan. Reflections on Strengthening Humanistic Care in Quality Nursing Service [J]. journal of nursing science, 2012, 27 (9): 1-2, 26.

[13] Liu Yilan, Wu Hongyan, Hu Deying. Thinking on Quality Management of Nursing Humanistic Care [J]. journal of nursing science. 2017, 32 (23): 1-4.

[14] Moran. Cultivation of Humanistic Quality of Post-80s Nurses [J]. Contemporary Nurses, 2012, 20 (4): 180-181.

[15] Yujie Guo, An li Jiang XuchunYe, et al. Study on the Application Effect of Nursing Humanistic Care Teaching Model [J]. Fudan Education Forum, 2014, 12 (2): 109-112.

\section{Biography}

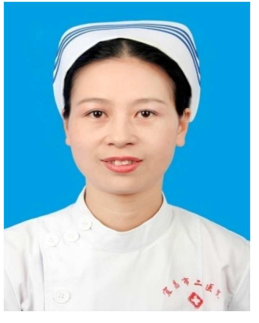

Xiaofeng Li (1969-), Yichang City, Hubei Province, China, director and chief nurse of the nursing department of Yichang Second People's Hospital, is a professor of the nursing department of Three Gorges University, editorial board member of journal of nursing science and other magazines, director of Hubei Nursing Association, standing member of Hubei Cancer Nursing Professional Committee, deputy director and secretary-general of Yichang Nursing Association, and chairman of Yichang Cancer Nursing Branch. She edited 5 nursing monographs, published more than 50 papers in core journals, presided over 5 scientific research topics, and won awards such as Hubei Provincial Progress Award. In April 2017, she was named the director of the national excellent nursing department.

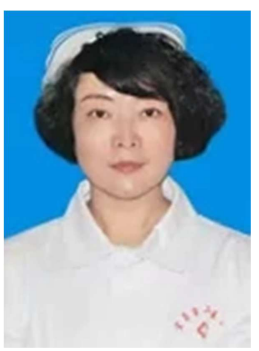

Lanian Chen (1970-), Yichang City, Hubei Province, China, director of nursing department of the second people's hospital of three Gorges university in Yichang city, deputy director of nursing division, undergraduatedegree research direction: clinical nursing and nursing management. 